\title{
Análise de rotas de coleta de resíduos sólidos domiciliares com uso de geoprocessamento
}

\author{
Route analysis of domiciliary solid residues in geographical \\ information systems
}

\author{
Alcides Pascoal Junior ${ }^{[a]}$, Paulo Costa de Oliveira Filho ${ }^{[b]}$ \\ [a] Engenheiro ambiental, Universidade Estadual do Centro (Unicentro), Irati, PR - Brasil, e-mail: alcidespascoal@yahoo.com.br \\ [b] Professor do Departamento de Engenharia Ambiental da Universidade Estadual do Centro-Oeste (Unicentro), Irati, PR - \\ Brasil, e-mail: paulocostafh@gmail.com
}

\section{Resumo}

Este trabalho teve como objetivo a avaliação do roteiro de coleta de resíduos sólidos domiciliares da região central da área urbana de Irati, PR, por meio da utilização de técnicas de rede em ambiente de Sistemas de Informações Geográficas. Foram aplicadas ferramentas de roteirização para a obtenção de distâncias replicadas no percurso atualmente utilizado pela prefeitura. Os resultados demonstraram valores consideráveis em relação às distâncias excedentes, chegando a 30,84\%, ultrapassando os limites aceitáveis para percursos improdutivos ou sem coleta efetiva, que é de no máximo $20 \%$. Os resultados obtidos podem proporcionar estimativas de custos em vários aspectos da cadeia relacionada ao roteiro de coleta de resíduos sólidos. As estimativas de custos com combustíveis foram analisadas, obtendose uma despesa excedente anual elevada. Além disso, o uso da modelagem de rede para a análise dos roteiros já existentes se mostra uma ferramenta útil para a obtenção de resultados importantes, além do convencional, que trata da simulação de novas rotas.

Palavras-chave: Roteiro de coleta. Sistemas de informações geográficas. Redes.

\section{Abstract}

This work had the objective of evaluating the collect script of urban solid waste at the central urban area of Irati, Parana State, using net techniques in geographic information system. Simulation tools for the attainment of distances talked 
back in the passage had been applied. The results had demonstrated considerable values in relation to the exceeding distances, arriving till $30.84 \%$, exceeding the acceptable limits for unproductive passages that have the maximum of $20 \%$. Results can provide estimates of costs in some aspects of the related chain to the collect scrip of solid residues. Fuel cost estimates had been analyzed, getting a raised annual exceeding expenditure. Moreover, the modeling of net used for the analysis of the existing scripts already, shows a sufficiently useful tool for the attainment of important results, beyond the conventional, that deals with new routes simulation.

Keywords: Collection route. Geographical information systems. Nets.

\section{Introdução}

O crescimento populacional desordenado nas cidades, com aglomerações de pessoas, maior fluxo de veículos e geração de resíduos, torna necessário o planejamento do transporte e coleta dos resíduos domiciliares em todo o perímetro urbano, mas principalmente na região central, onde o problema é constante e maior. A roteirização do sistema de coleta de resíduos sólidos domiciliares é uma ferramenta que reduz essas consequências da falta de planejamento.

Conforme Lopes (2008), há deficiências e necessidade de melhor planejamento no roteiro de coleta na área central do município, sendo considerada a região mais crítica, em virtude de vários aspectos, como intenso fluxo de veículos e pedestres.

Este estudo teve como objetivo analisar o atual roteiro de coleta de resíduos sólidos domiciliares na região central da área urbana do Município de Irati, PR. Utilizou para sua condução a ferramenta de rede em ambiente de sistema de informações geográficas, para simular e diagnosticar os percursos improdutivos e os custos excedentes com combustível para o período de um ano de coleta de resíduos sólidos.

\section{Fundamentação teórica}

\section{Definição dos itinerários de coleta}

O gerenciamento do lixo municipal é um conjunto articulado de ações normativas, operacionais, financeiras e de planejamento que uma administração municipal desenvolve, para coletar, segregar, tratar e dispor o lixo de sua cidade (VILHENA, 2002). Uma coleta mal planejada encarece o transporte, gera prejuízos e reclamações, prejudica o tratamento e a disposição final do lixo. A coleta de lixo e o seu transporte para áreas de tratamento ou destinação final são ações do serviço público municipal, de grande visibilidade para a população, que impedem o desenvolvimento de vetores transmissores de doenças que encontram alimento e abrigo no lixo.

O itinerário de coleta é o trajeto que o veículo coletor deve percorrer dentro de um mesmo setor, num mesmo período, transportando o máximo de lixo num mínimo de percurso improdutivo, com o menor desgaste possível para a guarnição e o veículo. Dá-se o nome de percurso improdutivo aos trechos em que o veículo não realiza coleta, servindo apenas para o deslocamento de um ponto a outro. É usual se elaborar para cada itinerário um roteiro de coleta, um roteiro gráfico da área, em mapa ou croqui, indicando seu início e término, percurso, pontos de coleta manual (sem acesso ao veículo, sendo o lixo coletado e carregado pelos coletores), trechos com percurso "morto" e manobras especiais, tais como ré e retorno (D'ALMEIDA, 2000).

Percurso "morto" é aquele repetido apenas para as manobras em respeito ao trânsito, com o objetivo de acesso a outros locais na sequência utilizada para a coleta. É admissível uma extensão total de percurso morto ou improdutivo correspondente a no máximo $20 \%$ da extensão total do percurso de coleta efetivamente produtivo. Podem-se utilizar os recursos da computação gráfica para o traçado desses roteiros (BRASIL, 2000). 
A delimitação do setor de coleta deve ser feita de modo a buscar o possível equilíbrio entre as massas de resíduos a serem coletadas em cada setor. Os obstáculos naturais e as divisões administrativas preexistentes devem, sempre que possível, servir como limites dos setores de coleta. A amplitude da área de um setor de coleta é função da estimativa da quantidade de resíduos gerada pela população estabelecida na referida área, bem como da extensão máxima que a equipe de garis consegue percorrer, em condições adequadas de trabalho, numa jornada usual. A soma dos percursos de coleta em um setor não deve ser superior a $25 \mathrm{~km}$.

O percurso de transporte dos resíduos dependerá da distância dos locais de geração até o de destinação final dos resíduos, bem como das velocidades efetivamente praticadas pelo veículo coletor. A velocidade da coleta está condicionada a obstáculos como topografia da área, intensidade do trânsito de veículos e pedestres, existência de locais de difícil acesso (ruas íngremes, locais sem condição para a entrada de veículos coletores convencionais, ou inadequados para a apresentação dos resíduos para a coleta, etc.). Levando-se em conta tais particularidades, para caminhões compactadores a velocidade média durante a operação de coleta normalmente varia entre 7 e $12 \mathrm{~km} / \mathrm{h}$. A velocidade de transporte dos resíduos dos locais de coleta até a destinação final varia com o tipo de via a ser percorrida e com o horário do transporte: para fins de planejamento, deverão ser adotados valores no intervalo entre 40 e $60 \mathrm{~km} / \mathrm{h}$ (D'ALMEIDA, 2000).

\section{Sistemas de Informações Geográficas}

Os Sistemas de Informações Geográficas (SIGs) prestam-se basicamente à captura, armazenamento, recuperação, transformação e visualização de dados espaciais do mundo real (BURROUGH, 1986). Esses sistemas oferecem alternativas de visualização de resultados de análises e dados espaciais que podem beneficiar a tomada de decisão aos gestores públicos.

Conforme Maguirre et al. (1991), um SIG pode ser definido a partir de três propriedades: a capacidade de apresentação cartográfica de informações complexas, uma base integrada de objetos espaciais e de seus atributos ou dados, e um conjunto de procedimentos e ferramentas de análise espacial.

Uma das aplicações dos SIGs são as funções de roteirização ou caminho ótimo ou econômico em modelos de dados configurados topologicamente para representar redes de transporte. O principal benefício dessas funções, comparando-se com outros métodos, é a utilização dos percursos espacializados ou mapas digitais devidamente editados em ambiente de sistema de informações geográficas, simplificando o processo de tomada de decisão na seleção das melhores alternativas econômicas e logísticas. Algumas dessas funções permitem o cálculo das distâncias ou comprimentos de linhas que representam os percursos realizados por caminhões coletores, bem como identificar trechos de linhas repetidos com bastante facilidade.

\section{Aplicações de rede ao sistema de coleta de lixo}

O verdadeiro poder dos SIGs advém da habilidade de executarem análises e operações espaciais complexas, o que os distingue de outros sistemas também capazes de manipular dados espaciais, como os CADs e demais sistemas de cartografia digital. Nesse contexto, os SIGs são um poderoso aliado no processo de planejamento, organizando as informações correlatas sob a forma de uma base de dados espaciais no formato digital e disponibilizando um vasto elenco de recursos avançados para simulação e otimização. Problemas de transporte são modelados utilizando-se uma estrutura de redes por onde os recursos escoam. Uma rede é uma representação gráfica baseada em feições lineares - arcos - às quais se associam valores. Esses valores podem representar distâncias, custos, tempo, ganhos, despesas ou outros atributos que se acumulem linearmente ao longo do percurso da rede. A soma desses valores entre a origem e o destino pode, então, ser minimizada. A busca do menor caminho, definida como o melhor, ou ainda o mais curto, o mais rápido, ou o mais econômico trajeto entre dois pontos, é uma das formas tradicionais de se otimizar um sistema de redes (DYSTRA, 1984).

Rev. Acad., Ciênc. Agrár. Ambient., Curitiba, v. 8, n. 2, p. 131-144, abr./jun. 2010 
Rocha et al. (2004) obtiveram bons resultados no ambiente Saga (Sistema de Análise Geoambiental), com aplicações de rede para planejamento do transporte de lixo no município de Mangaratiba, RJ. Brasileiro e Lacerda (2008) apresentaram reduções percentuais de até $41 \%$ na distância total percorrida na coleta de lixo do município de Ilha Solteira, SP, utilizando o sistema TransCAD.

\section{Softwares livres para roteirização}

Nos últimos anos foram desenvolvidos vários aplicativos de domínio público para as mais variadas aplicações. O Sistema de Processamento de Informações Georreferenciadas (Spring) é um SIG no estado da arte com funções de processamento de imagens, análise espacial, modelagem numérica de terreno e consulta a bancos de dados espaciais (CAMARA, 1996).

Atualmente, já existem no mercado alguns softwares para a elaboração de roteiros ou itinerários otimizados de veículos de coleta de lixo. Sua utilização permite definir um conjunto de roteiros que atendem a uma região, assegurando percursos com menor custo (número de viagens, número de veículos e tempo total) e atendendo às restrições de circulação dos veículos nas ruas da cidade, de capacidade dos caminhões e de duração da jornada de trabalho da guarnição.

Em geral, os softwares são dotados de recursos de SIG, que permitem representar, graficamente, por meio de mapas na tela do computador, os dados do sistema viário e dos pontos de atendimento.

\section{Materiais e métodos}

\section{Área de estudo}

O município de Irati localiza-se na macrorregião sul e mesorregião sudeste paranaense e microrregião de Irati. De acordo com dados da prefeitura, em 2009 a população estimada da cidade era de 58.136 habitantes, sendo 45.299 na área urbana e 12.837 na área rural. A cidade de Irati encontra-se entre as seguintes

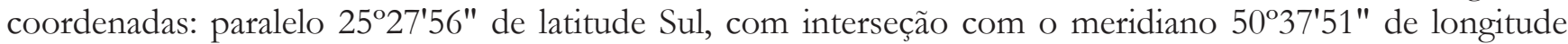
Oeste (IRATI, 2009). A área de estudo restringiu-se ao bairro Centro, considerado pelo responsável técnico de gerenciamento de resíduos do município como a região crítica (Figura 1).

\section{Caracterização da coleta em Irati}

O serviço de coleta e destino final dos resíduos sólidos urbanos é de responsabilidade da Prefeitura Municipal de Irati. O recolhimento é realizado de segunda a sábado, e diariamente na área central, em virtude do grande número de residências e comércio em geral.

De acordo com Lopes (2008), o transporte de resíduos é executado com caminhões compactadores com capacidade média de $5 \mathrm{~m}^{3}$ cada; cada veículo conta com três funcionários, sendo um motorista e dois garis responsáveis pelo recolhimento do material na área urbana. O mesmo autor ainda complementa que, após coletar o material, os caminhões se deslocam até o aterro sanitário pela BR 277, num percurso de 15 $\mathrm{km}$, seguindo $6 \mathrm{~km}$ por estrada secundária em bom estado de conservação. O local de transbordo fica localizado em Pinho de Cima, área rural, distante $21 \mathrm{~km}$ da sede, perfazendo um percurso médio de 80 a $100 \mathrm{~km}$ desde a coleta até o destino final. Observou, por meio de saídas de campo, que a frequência de coleta está mal planejada em certos pontos da área urbana, principalmente na área central, em que o caminhão coletor percorre de quatro a cinco vezes o mesmo roteiro. Alguns fatores apontaram as dificuldades encontradas pelos funcionários no período em que é realizada a coleta, como:

- ruas íngremes e de difícil acesso; 
- trânsito intenso de veículos entre 9h e 15h;

- resíduos acondicionados em tambores com peso acima de $100 \mathrm{~kg}$, dificultando o trabalho de carregamento dos materiais;

- latões abertos, ocasionando o acúmulo de água em dias chuvosos;

- animais soltos (cães), colocando em risco a saúde do gari;

- objetos perfurocortantes (cacos de vidro) sem acondicionamento adequado e misturados com os resíduos orgânicos;

- materiais de varrição, poda verde, resíduos de floricultura colocados com os resíduos domiciliares;

- materiais acondicionados em sacolas plásticas pelas residências sem o devido cuidado, facilitando o ataque de animais, que espalham o material em vias públicas.

\section{Estado do Paraná}
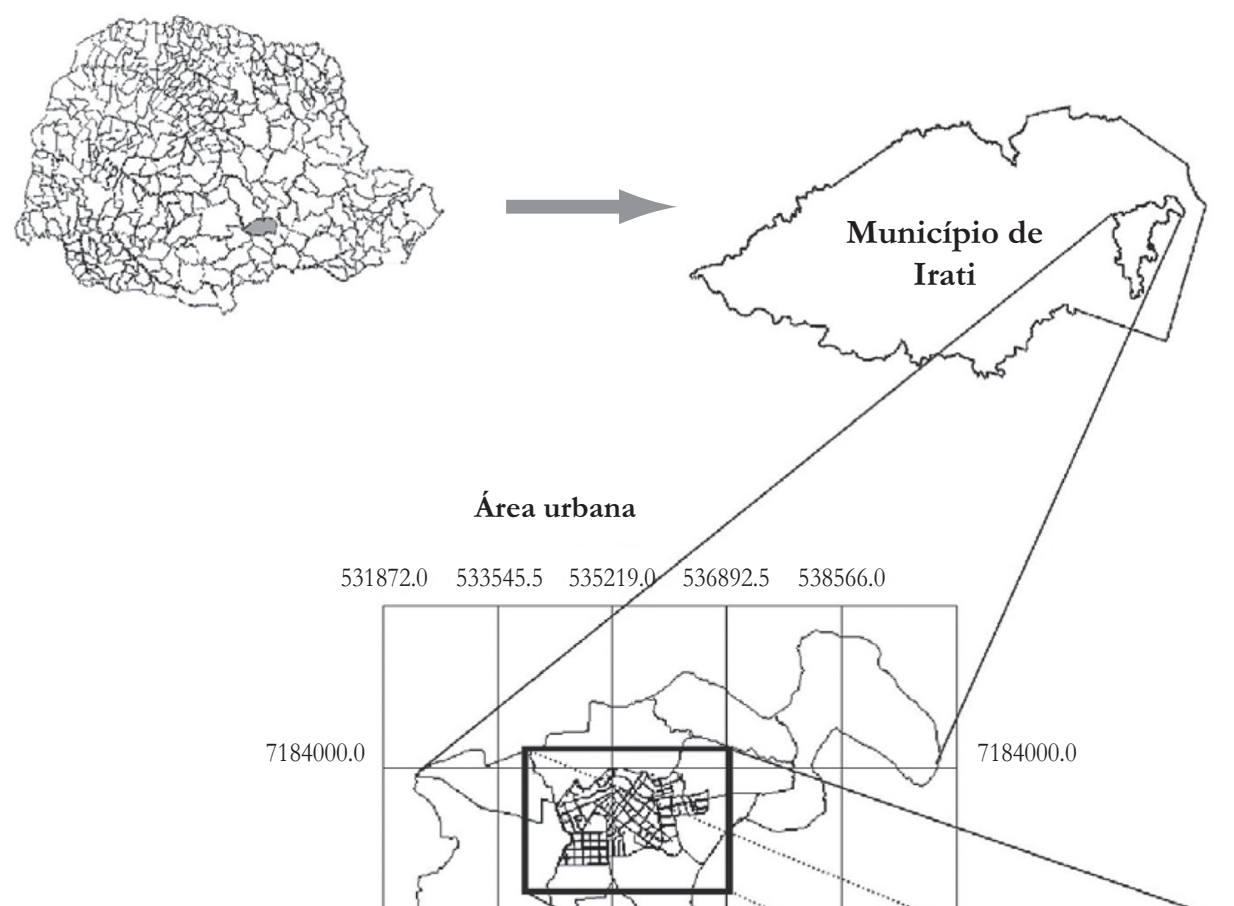

7181641

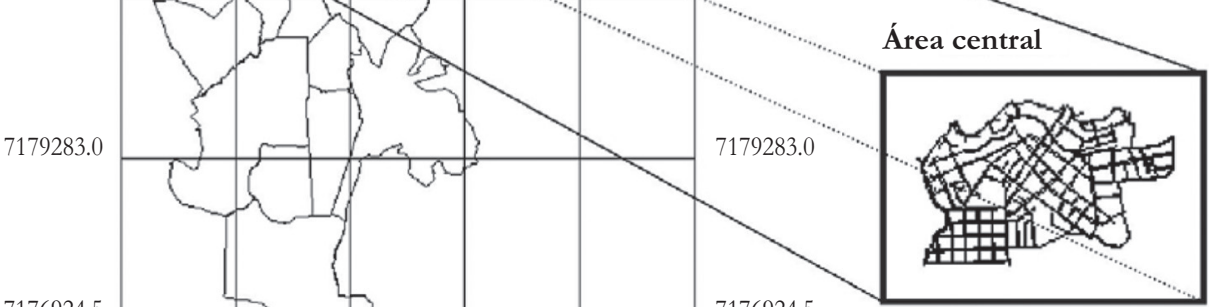

7176924.5

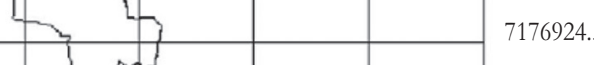

6924.5

$531872.0 \quad 533545.5 \quad 535219.0 \quad 536892.5 \quad 538566.0$

7174566.0

Figura 1 - Localização da área de estudo 


\section{Metodologia}

Inicialmente, foi realizada uma entrevista com o responsável técnico pelo gerenciamento de resíduos sólidos do município, para a definição do local mais problemático da área urbana em relação à coleta, para ser utilizada no presente estudo.

A seguir, em campo, foram acompanhados os itinerários do caminhão de coleta de resíduos sólidos, para reconhecimento dos itinerários ou roteiros atuais, a partir do horário de saída até o retorno à garagem. O caminhão de coleta utilizado é da marca Wolkswagen ${ }^{\circledR}$, modelo Worker 13.180 Euro III, ano 2007, com caçamba compactadora, capacidade média de $5 \mathrm{~m}^{3}$ de volume, e consumo médio de combustível de $4 \mathrm{~km} / \mathrm{L}$ de óleo diesel (Figura 2). Após levantamento de preço realizado em postos de combustível da região, o valor médio estimado por litro de óleo diesel verificado foi de $\mathrm{R} \$ 2,02$.

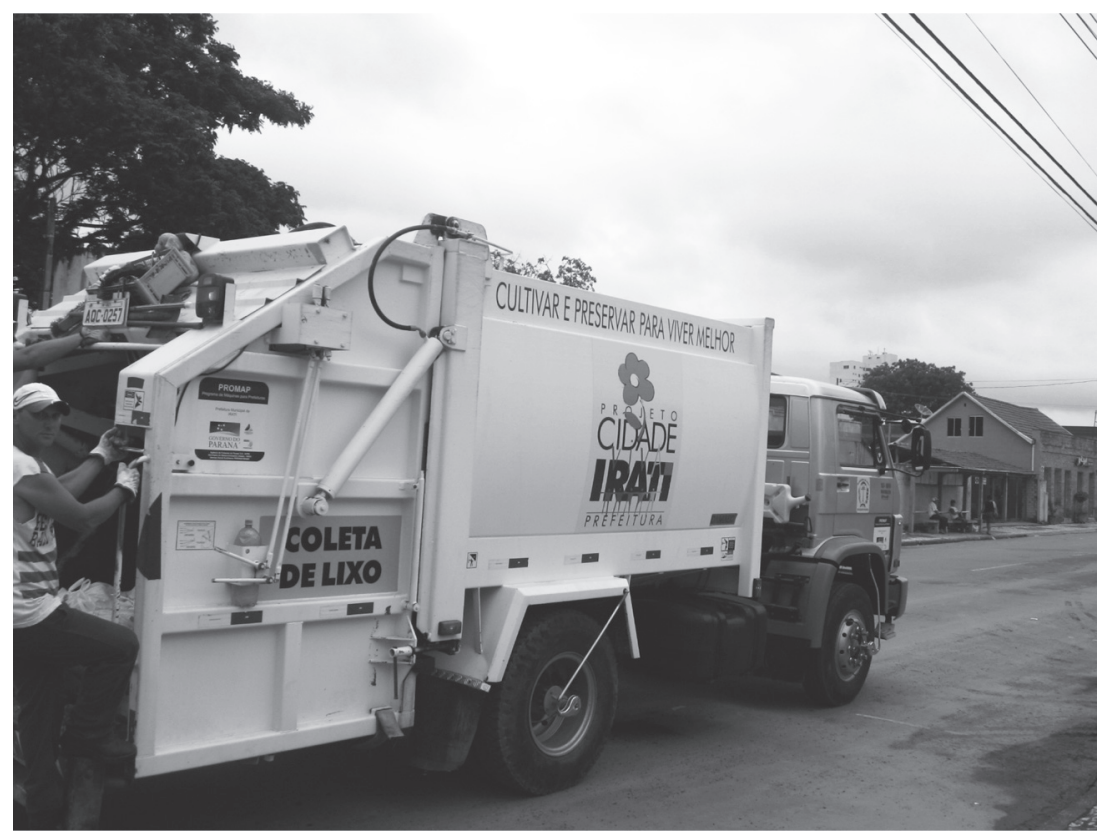

Figura 2 - Caminhão de coleta que segue o itinerário estudado

Foi fornecida pela Secretaria de Obras e Serviços Urbanos, localizada no Parque de Máquinas, a relação dos logradouros que devem ser atendidos na região. Para a realização do presente estudo foi utilizado um mapa digital da área urbana de Irati em formato vetorial (.dwg), fornecido pelo Departamento de Geoprocessamento da prefeitura.

\section{Estruturação do modelo de dados no SIG}

Foi implementado um modelo de dados espacial específico para a aplicação de ferramentas de rede, em ambiente de sistema de informações geográficas no aplicativo Spring versão 5.1.3, com uso do gerenciador de dados Access. A área para a abrangência do projeto limitou-se à região central da área urbana do município, selecionada por causa do intenso volume de resíduos coletado e por ser, de acordo com os responsáveis técnicos, a área que apresenta maiores dificuldades.

Com base no mapa digital, realizou-se a preparação do arquivo vetorial representativo da rede de logradouros e a edição de linhas ou arcos e nós para ajustamento do modelo arco-nó, resultando em uma 
malha de arcos e nós interligados, de forma a permitir a realização de análises e simulações de roteamento. Este modelo arco-nó apresenta de forma virtual, no sistema, na tela do computador, a logística de trânsito da região de estudo. Esta preparação necessária dos dados gráficos (arcos e nós) é também denominada de edição topológica e é realizada para que o sistema seja representativo e fiel à realidade que se deseja representar. Assim sendo, as linhas, também chamadas de arcos, devem estar unidas ou conectadas para que não hajam interrupções nos percursos simulados pelo sistema, e os nós devem representar os cruzamentos e extremidades entre as linhas ou logradouros.

Após a edição topológica do modelo arco-nó da rede, foi realizada a comparação e análise entre o caminho percorrido pelo caminhão para se chegar aos pontos de coleta, e aquele utilizado para manobras de trânsito, percorrendo repetidas vezes os mesmos logradouros. O comprimento dos arcos, ou linhas que representam os percursos realizados pelo caminhão de coleta, foi dimensionado no sistema, sendo detectados os caminhos excedentes ou percursos considerados improdutivos. Para isso, utilizou-se a ferramenta de roteirização ou custo mínimo do módulo de rede do software Spring. O Quadro 1 exibe o roteiro oficial executado atualmente no Centro da cidade.

Quadro 1 - Sequência do percurso total de coleta de resíduos sólidos no centro de Irati, PR

\begin{tabular}{|c|c|c|c|c|c|}
\hline 1 & 19 de Dezembro & 15 & Coronel Grácia & 29 & Coronel Emílio Gomes \\
\hline 2 & Alfredo Bufrem & 16 & XV de Novembro & 30 & XV de Julho \\
\hline 3 & 24 de maio & 17 & Carlos Thoms & 31 & Alfredo Kaminski \\
\hline 4 & Frederico Koch & 18 & Sebastião Mendes & 32 & Dr. Vicente Machado \\
\hline 5 & Rui Barbosa & 19 & Angelo Luiz Bozza & 33 & Dr. Fernando S. Rocha \\
\hline 6 & Dr. Correia & 20 & Santos Dumont & 34 & Judith Amaral Capellina \\
\hline 7 & Barão do Rio Branco & 21 & 7 de setembro & 35 & Mal. Deodoro \\
\hline 8 & Dr. Munhoz da Rocha & 22 & Rua da Liberdade & 36 & Cons. Zacarias \\
\hline 9 & Benjamim Constant & 23 & Manoel Ribas & 37 & Ezequiel Andrade Gomes \\
\hline 10 & Alexandre Pavelski & 24 & Edgar Távora & 38 & João Cavalin Zarpellon \\
\hline 11 & Duque de Caxias & 25 & André Filipaki & 39 & João Batista Anciutti \\
\hline 12 & Maria Pires Farah & 26 & Olímpia Amaral Gruber & 40 & Palmeira \\
\hline 13 & José Galicioli & 27 & Campo Largo & 41 & Turibio Baptista \\
\hline 14 & Senhorinha Cabral Piechi & 28 & Nalib Badir Maluf & & \\
\hline
\end{tabular}

A área foi dividida em dois setores (Setor 1 e 2), tendo em vista a dificuldade do software em processar todo o caminho de uma só operação na sua totalidade. Essa divisão não influenciou a sequência das ruas ou logradouros listados no itinerário oficial. Desta forma, o percurso total para a coleta de resíduos sólidos no Centro de Irati foi dividido em dois setores: lado esquerdo e direito da Rua Marechal Deodoro. 
A seguir foi obtido o relatório de dados, por meio da execução da ferramenta de cálculo de caminhos ótimos de rede, que registra a simulação do roteiro, detalhando as linhas e as distâncias percorridas em sequência. Na próxima etapa, os dados foram transportados para uma planilha no software Excel, na qual foi realizada uma verificação de caminhos repetidos no roteiro, por meio da detecção de repetições de arcos ou linhas fornecidas pelo relatório. A quantidade de repetições foi multiplicada pelo comprimento de cada linha, com a finalidade de obtenção da distância excedente, ou seja, daquele percurso adicional, considerado improdutivo, realizado pelo caminhão.

A partir das distâncias excedentes, ou seja, dos percursos improdutivos, foi feita uma análise do custo excedente, considerando apenas os gastos com combustível. O resultado do estudo considera trecho improdutivo quando o caminhão coletor passa mais de uma vez por um mesmo trecho de percurso - situações como rua sem saída e avenida com mão dupla, casos em que o caminhão necessita repetir o trecho, estão incluídos nestes $20 \%$ de tolerância.

\section{Resultados e discussão}

As Tabelas 1 e 2 apresentam a sequência de linhas representativas dos percursos utilizados atualmente no sistema de coleta de resíduos sólidos na região central da cidade, nos setores 1 e 2 , respectivamente por apenas um caminhão de lixo. Como resultado, cada quadro apresenta a distância total percorrida em metros por setor.

As Figuras 3 e 4 apresentam as telas do aplicativo utilizado, com a simulação dos percursos dos setores 1 e 2, e o cálculo das distâncias dos trajetos repetidos.

Tabela 1 - Sequência dos 156 arcos ou linhas representativas dos logradouros que formam todo o percurso realizado pelo caminhão no Setor 1

\begin{tabular}{lrrrrrrrrrrrr}
\hline Trechos & \multicolumn{7}{c}{ Lista de linhas codificadas que formam cada trecho do percurso no Setor 1 } \\
\hline $\mathbf{0 1}$ & 231 & 137 & 155 & 234 & 156 & 196 & 193 & 191 & 191 & 193 & 197 & 201 \\
$\mathbf{0 2}$ & 183 & 208 & 211 & 241 & 163 & 262 & 259 & 251 & 121 & 120 & 88 & 70 \\
$\mathbf{0 3}$ & 278 & 67 & 58 & 55 & 50 & 49 & 49 & 50 & 181 & 59 & 59 & 181 \\
$\mathbf{0 4}$ & 52 & 54 & 223 & 56 & 59 & 273 & 60 & 60 & 69 & 71 & 267 & 260 \\
$\mathbf{0 5}$ & 256 & 121 & 120 & 120 & 117 & 122 & 23 & 123 & 271 & 271 & 249 & 250 \\
$\mathbf{0 6}$ & 251 & 261 & 266 & 269 & 279 & 90 & 95 & 93 & 276 & 107 & 108 & 113 \\
$\mathbf{0 7}$ & 113 & 109 & 75 & 77 & 78 & 65 & 65 & 78 & 89 & 111 & 112 & 105 \\
$\mathbf{0 8}$ & 101 & 101 & 105 & 106 & 106 & 105 & 101 & 104 & 104 & 101 & 103 & 79 \\
$\mathbf{0 9}$ & 133 & 81 & 128 & 82 & 131 & 131 & 82 & 82 & 131 & 115 & 122 & 23 \\
$\mathbf{1 0}$ & 123 & 271 & 147 & 185 & 126 & 225 & 184 & 247 & 247 & 184 & 257 & 261 \\
$\mathbf{1 1}$ & 229 & 240 & 170 & 241 & 211 & 208 & 174 & 228 & 203 & 204 & 266 & 261 \\
$\mathbf{1 2}$ & 257 & 184 & 149 & 244 & 243 & 146 & 145 & 218 & 150 & 152 & 166 & 166 \\
$\mathbf{1 3}$ & 167 & 165 & 235 & 263 & 253 & 246 & 245 & 245 & 252 & 151 & 185 & 147 \\
\hline
\end{tabular}

Distância do percurso: $16.694,73 \mathrm{~m}$

Rev. Acad., Ciênc. Agrár. Ambient., Curitiba, v. 8, n. 2, p. 131-144, abr./jun. 2010 
Tabela 2 - Sequência dos 108 arcos ou linhas representativas dos logradouros que formam todo o percurso realizado pelo caminhão no Setor 2

\begin{tabular}{lrrrrrrrrrrrrr}
\hline Trechos & \multicolumn{10}{c}{ Lista de linhas codificadas que formam cada trecho do percurso no Setor 2 } \\
\hline $\mathbf{0 1}$ & 275 & 276 & 107 & 74 & 76 & 75 & 77 & 77 & 13 & 9 & 8 & 6 \\
$\mathbf{0 2}$ & 64 & 14 & 17 & 80 & 80 & 80 & 16 & 16 & 80 & 15 & 5 & 62 \\
$\mathbf{0 3}$ & 296 & 221 & 186 & 242 & 17 & 15 & 5 & 4 & 7 & 7 & 61 & 11 \\
$\mathbf{0 4}$ & 63 & 65 & 10 & 86 & 61 & 4 & 42 & 42 & 62 & 1 & 2 & 221 \\
$\mathbf{0 5}$ & 296 & 38 & 37 & 45 & 46 & 48 & 25 & 28 & 26 & 26 & 29 & 47 \\
$\mathbf{0 6}$ & 33 & 33 & 47 & 30 & 41 & 41 & 30 & 47 & 31 & 31 & 33 & 40 \\
$\mathbf{0 7}$ & 39 & 37 & 286 & 290 & 295 & 284 & 282 & 287 & 285 & 293 & 292 & 30 \\
$\mathbf{0 8}$ & 29 & 28 & 25 & 48 & 280 & 53 & 86 & 11 & 63 & 78 & 89 & 111 \\
$\mathbf{0 9}$ & 112 & 105 & 102 & & & & & & & & &
\end{tabular}

Distância do percurso: $12.325,831055$ m

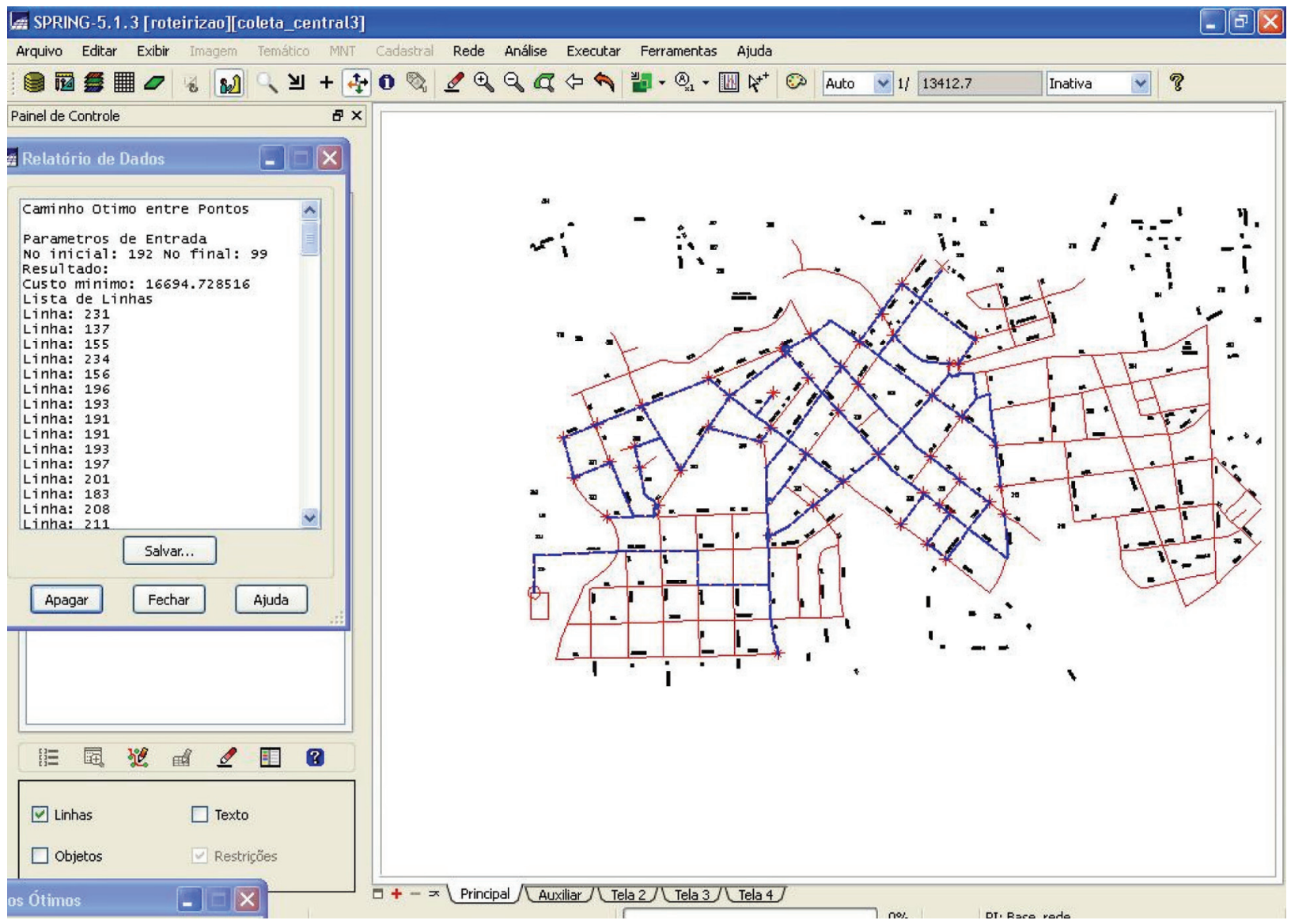

Figura 3 - Tela do software Spring ${ }^{\circledR}$ realçando a representação de cada trecho do roteiro do Setor 1 


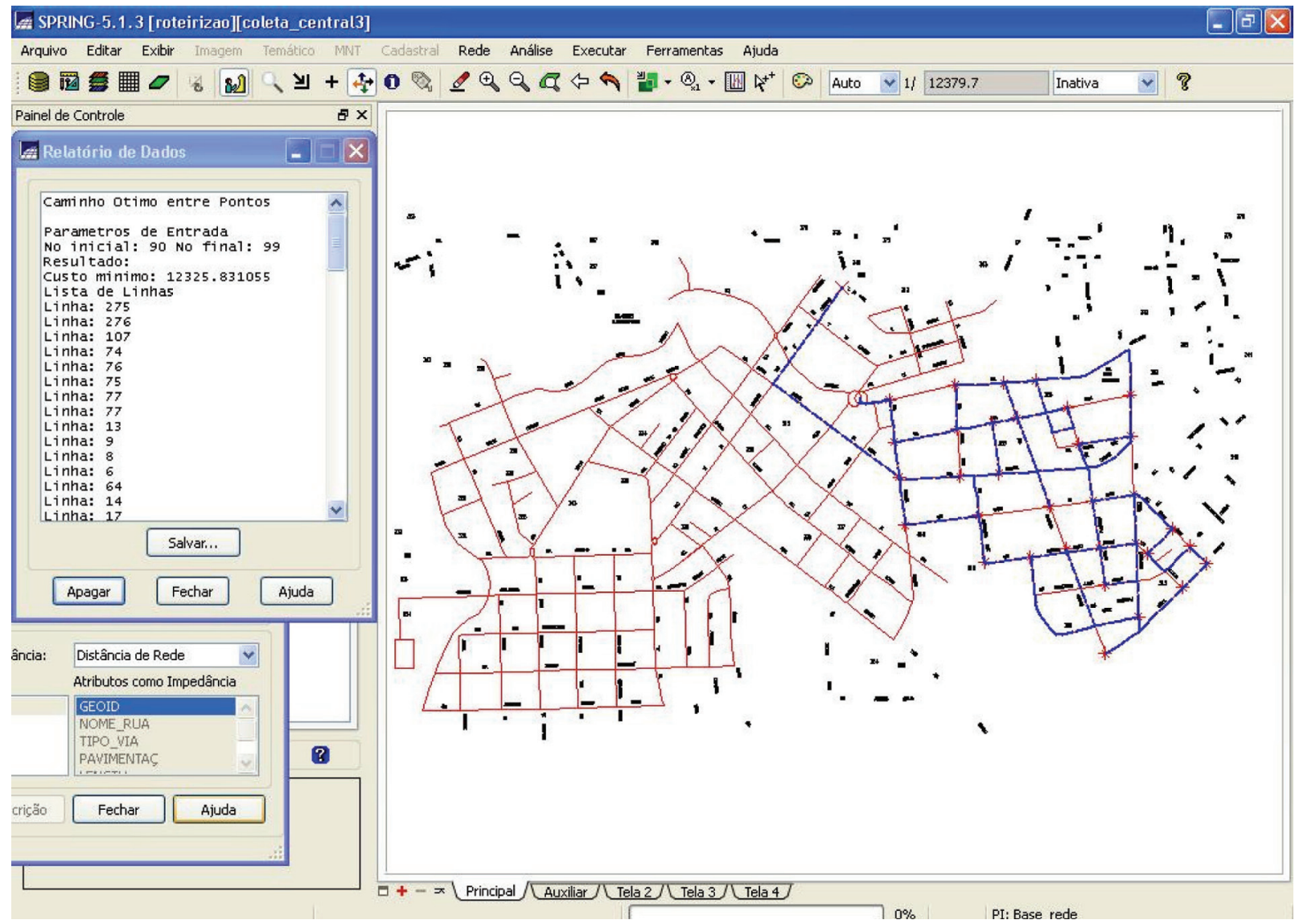

Figura 4 - Tela do software Spring ${ }^{\circledR}$ realçando a representação de cada trecho do roteiro do setor 2

A seguir, as linhas ou trechos repetidos foram identificados e contabilizados como percursos improdutivos. Os resultados são apresentados nas Tabelas 3 e 4 . A Tabela 5 apresenta os resultados de ambos os setores, e também o percentual de percurso improdutivo ou excedente calculado para o trajeto utilizado no Centro da cidade. Como pode ser observado, o percentual de percurso improdutivo excede consideravelmente os $20 \%$ admissíveis, conforme Brasil (2000).

Tabela 3 - Quantidade de repetições, comprimento de cada linha e o percurso excedente no Setor 1

(continua)

\begin{tabular}{cccc}
\hline Linha & Repetições & $\begin{array}{c}\text { Comprimento } \\
\text { (metros) }\end{array}$ & $\begin{array}{c}\text { Excedente } \\
\text { (metros) }\end{array}$ \\
\hline $\mathbf{2 9 8}$ & 4 & 83,33 & 249,99 \\
$\mathbf{1 0 1}$ & 4 & 148,67 & 446,01 \\
$\mathbf{1 0 4}$ & 2 & 104,99 & 104,99 \\
$\mathbf{1 0 5}$ & 4 & 151,53 & 454,59 \\
$\mathbf{1 0 6}$ & 2 & 223,48 & 223,48 \\
$\mathbf{1 1 2}$ & 2 & 86,02 & 86,02 \\
\hline
\end{tabular}

Rev. Acad., Ciênc. Agrár. Ambient., Curitiba, v. 8, n. 2, p. 131-144, abr./jun. 2010 
Tabela 3 - Quantidade de repetições, comprimento de cada linha e o percurso excedente no Setor 1

(conclusão)

\begin{tabular}{|c|c|c|c|}
\hline Linha & Repetições & $\begin{array}{l}\text { Comprimento } \\
\text { (metros) }\end{array}$ & $\begin{array}{c}\text { Excedente } \\
\text { (metros) }\end{array}$ \\
\hline 113 & 2 & 81,50 & 81,50 \\
\hline 115 & 2 & 198,03 & 198,03 \\
\hline 120 & 3 & 80,50 & 161,01 \\
\hline 121 & 2 & 108,47 & 108,47 \\
\hline 122 & 3 & 86,89 & 173,78 \\
\hline 123 & 2 & 10,85 & 10,85 \\
\hline 125 & 2 & 4,94 & 4,94 \\
\hline 131 & 3 & 119,04 & 238,07 \\
\hline 147 & 2 & 239,80 & 239,80 \\
\hline 166 & 2 & 87,47 & 87,47 \\
\hline 181 & 2 & 83,09 & 83,09 \\
\hline 184 & 3 & 61,92 & 123,82 \\
\hline 185 & 2 & 126,02 & 126,02 \\
\hline 191 & 2 & 126,02 & 126,02 \\
\hline 193 & 2 & 118,33 & 118,33 \\
\hline 208 & 2 & 72,49 & 72,45 \\
\hline 211 & 2 & 33,74 & 33,74 \\
\hline 23 & 2 & 5,11 & 5,11 \\
\hline 241 & 2 & 4,82 & 4,82 \\
\hline 245 & 2 & 122,51 & 122,51 \\
\hline 247 & 2 & 97,32 & 97,32 \\
\hline 251 & 2 & 194,35 & 194,35 \\
\hline 257 & 2 & 70,19 & 70,19 \\
\hline 261 & 3 & 79,13 & 158,25 \\
\hline 266 & 2 & 154,63 & 154,63 \\
\hline 271 & 3 & 7,712 & 15,42 \\
\hline 49 & 2 & 146,55 & 146,55 \\
\hline 50 & 2 & 159,03 & 159,02 \\
\hline 59 & 3 & 40,92 & 81,84 \\
\hline 60 & 2 & 129,18 & 129,18 \\
\hline 65 & 2 & 139,98 & 139,98 \\
\hline 78 & 2 & 8,91 & 8,91 \\
\hline 82 & 3 & 5,55 & 11,10 \\
\hline
\end{tabular}

Total de percurso improdutivo: $5.051,68 \mathrm{~m}$ 
Tabela 4 - Quantidade de repetições, comprimento de cada linha e o percurso excedente no Setor 2

\begin{tabular}{|c|c|c|c|}
\hline Linha & Repetições & $\begin{array}{l}\text { Comprimento } \\
\text { (metros) }\end{array}$ & $\begin{array}{c}\text { Excedente } \\
\text { (metros) }\end{array}$ \\
\hline 11 & 2 & 42,090919 & 42,090919 \\
\hline 15 & 2 & 115,382138 & 115,38214 \\
\hline 16 & 2 & 136,257492 & 136,25749 \\
\hline 17 & 2 & 97,639161 & 97,639161 \\
\hline 221 & 2 & 17,154896 & 17,154896 \\
\hline 25 & 2 & 24,822472 & 24,822472 \\
\hline 26 & 2 & 254,367432 & 254,36743 \\
\hline 28 & 2 & 243,930808 & 243,93081 \\
\hline 29 & 2 & 136,997151 & 136,99715 \\
\hline 296 & 2 & 162,752195 & 162,7522 \\
\hline 30 & 3 & 40,601496 & 81,202992 \\
\hline 31 & 2 & 115,217293 & 115,21729 \\
\hline 33 & 3 & 97,822968 & 195,64594 \\
\hline 37 & 2 & 127,877172 & 127,87717 \\
\hline 4 & 2 & 117,540674 & 117,54067 \\
\hline 41 & 2 & 129,206059 & 129,20606 \\
\hline 42 & 2 & 117,140871 & 117,14087 \\
\hline 47 & 3 & 112,973981 & 225,94796 \\
\hline 48 & 2 & 115,183461 & 115,18346 \\
\hline 5 & 2 & 175,136584 & 175,13658 \\
\hline 61 & 2 & 77,376778 & 77,376778 \\
\hline 62 & 2 & 155,441804 & 155,4418 \\
\hline 63 & 2 & 186,932187 & 186,93219 \\
\hline 7 & 2 & 158,9955 & 158,9955 \\
\hline 77 & 2 & 109,161363 & 109,16136 \\
\hline 80 & 4 & 151,238135 & 453,71441 \\
\hline 86 & 2 & 124,610336 & 124,61034 \\
\hline
\end{tabular}

Total de Percurso Improdutivo: $3.897,73 \mathrm{~m}$

Estes resultados permitiram uma avaliação do gasto excedente de combustível, considerando o rendimento médio do caminhão e o custo médio do diesel na região. Portanto, sendo o valor médio do óleo diesel na região de $\mathrm{R} \$ 2,02$, o rendimento do caminhão de $4 \mathrm{~km} / \mathrm{L}$, e o percurso excedente ou improdutivo total 8.949,41 m ou 8,9 km, o consumo excedente por dia é de 2,24 L. Considerando 310 dias de coleta por ano, tem-se um custo anual excedente de $\mathrm{R} \$ 1.410,50$ ('Tabela 6). 
Tabela 5 - Distâncias percorridas e percentual total de percurso excedente ou improdutivo

\begin{tabular}{lccc}
\hline Distância & Setor 1 (metros) & Setor 2 (metros) & Total (metros) \\
\hline Percorrida & $16.694,73$ & $12.325,83$ & $29.020,56$ \\
Excedente & $5.051,68$ & $3.897,73$ & $8.949,41$ \\
\hline \multicolumn{2}{l}{ Percentual de percurso improdutivo: $30,84 \%$} & \\
\hline
\end{tabular}

Tabela 6 - Gasto excedente de combustível em um ano de coleta de resíduos sólidos somente na região central da cidade

\begin{tabular}{lr}
\hline Rendimento & $4 \mathrm{~km} / \mathrm{L}$ \\
Consumo excedente & $2,24 \mathrm{~L} / \mathrm{dia}$ \\
Valor médio de óleo diesel & $\mathrm{R} \$ 2,02$ \\
Custo diário & $\mathrm{R} \$ 4,55$ \\
\hline Custo anual excedente & $\mathrm{R} \$ 1.410,50$ \\
\hline
\end{tabular}

\section{Conclusões}

O sistema utilizado e a modelagem de rede permitiram uma avaliação da repetição de trechos do percurso do roteiro atual do sistema de coleta de resíduos sólidos da área central da área urbana do município de Irati. O percentual de percurso improdutivo obtido foi de 30,84\%, ultrapassando consideravelmente os $20 \%$ admissíveis. A despesa excedente anual obtida, somente considerando os gastos com combustível, no percurso estudado foi de $\mathrm{R} \$ 1.410,50$.

Este trabalho apresenta como contribuição a utilização das ferramentas de rede em ambiente SIG. Trata não somente o modo mais convencional de simulação de novas rotas, a partir da configuração da modelagem de um sistema de rede e suas impedâncias, mas apresenta uma alternativa operacional para a análise econômica de percursos de coleta de resíduos sólidos já existentes e utilizados em áreas urbanas. Sua finalidade foi a de se discutir e modificar as logísticas para a coleta de resíduos sólidos.

\section{Recomendações}

Neste estudo, procurou-se analisar o roteiro utilizado na região central da cidade de Irati e avaliar somente os custos excedentes de combustível em função da caracterização de percursos improdutivos. Outros critérios podem ser considerados, tais como depreciação da frota de veículos, pagamento de horas extras dos funcionários, entre outros que podem enfatizar ainda mais a importância do tema. 


\section{Agradecimentos}

Os autores agradecem à Prefeitura Municipal de Irati e em especial ao técnico Osnei Abel Lopes, da Secretaria de Ecologia e Meio Ambiente, pelas informações e apoio a este estudo.

\section{Referências}

BRASIL. Ministério do Meio Ambiente. Curso: modelo de gestão integrada dos resíduos sólidos urbanos. Brasília: Ministério do Meio Ambiente, 2000.

BRASILEIRO, L. A.; LACERDA, M. G. Análise do uso de SIG no roteamento dos veículos de coleta de resíduos sólidos domiciliares, 2008. Disponível em: <http://www.scielo.br/pdf/esa/v13n4/a02v13n4.pdf>. Acesso em: 20 nov. 2009.

BURROUGH, P. A. Principles of geographical information systems for land resources assessment. New York: Oxford University Press, 1986.

CAMARA, G. et al. Spring: integrating remote sensing and GIS by object-oriented data modelling. Computers \& Graphics, v. 20, n. 3, p. 395-403, 1996.

D’ALMEIDA, M. L. O. (Coord.). Lixo municipal: manual de gerenciamento integrado. 2. ed. Brasília: CEMPRE, 2000.

DYKSTRA, D. P. Mathematical programing for natural resource management. New York: McGraw-Hill, 1984.

IRATI. Localização geográfica. 2009. Disponível em: < http://www.irati.pr.gov.br/municipio/localizaçaogeografica. asp>. Acesso em: 22 nov. 2009.

LOPES, O. A. Estudo da gestão de resíduos sólidos urbanos domiciliares na área urbana do município de Irati, no período de 2005 a 2008. 2008. 75 f. Monografia (Especialização em Administração Pública) - Faculdade Padre João Bagozzi, Curitiba, 2008.

MAGUIRRE, D. J.; GOODCHILD, N. S.; RHIND, D. W. Geographical informations systems: principals and aplications. London: Longman, 1991.

ROCHA, C. H. B.; BRITO FILHO, L. F. de; SILVA, J. X. da. Geoprocessamento aplicado à seleção de locais para implantação de aterros sanitários: o caso de Mangaratiba - RJ. In: SILVA, J. X. da; ZAIDAN, R. T. (Org.). Geoprocessamento e análise ambiental: aplicações. Rio de Janeiro: Bertrand Brasil, 2004. p. 153-156.

VILHENA, A. (Coord.). Guia da coleta seletiva de lixo. Brasília: CEMPRE, 2002.

Recebido: 15/01/2010

Received: 01/15/2010

Aprovado: 26/03/2010

Approved: 03/26/2010 